\title{
Formulação orgânica eficiente para controle de Cochonilha (Dactylopius coccus) em plantas ornamentais: estudo de caso em Hibiscus rosa- sinensis $\mathrm{L}$.
}

\author{
Efficient organic formulation to Cochineal control (Dactylopius coccus) in \\ ornamental plants: case study on Hibiscus rosa -sinensis L.
}

DOI 10.5935/2446-4775.20170014

'BRAGA, Gilberto S. ${ }^{*}$; ${ }^{1}$ COSTA, Marco Antônio G.; ${ }^{1}$ ROCHA, Albericio N.

${ }^{1}$ FIOCRUZ, Instituto de Tecnologia em Fármacos/Farmanguinhos/CTM, Jacarepaguá, Rio de Janeiro, RJ, Brasil.

*Correspondências: gbraga@far.fiocruz.br

\section{Resumo}

O Complexo Tecnológico de Medicamentos-CTM é a unidade fabril do Instituto de Tecnologia em Fármacos/Farmanguinhos. Dentro do seu campus, o cuidado das áreas verdes deve ser conduzido de forma orgânica, sem a ação de agrotóxicos ou outros tipos de substâncias que possam prejudicar, em algum momento, a rotina fabril. Neste trabalho, propomos uma formulação orgânica para o controle de pragas e vetores, com a utilização de insumos naturais.

Palavras-chave: Formulação orgânica. Biodefensivo. Cochonilha. Hibiscus rosa-sinensis L.

\begin{abstract}
The Medicines Technological Complex - MTC is the production plant of the Institute of Drug Technology/Farmanguinhos. Within its campus, the green areas should be taken care organically, without the action of pesticides or other substances that can harm the manufacturing routine. In this paper we propose an organic formulation to control pests and vectors containing natural ingredients.
\end{abstract}

Keywords: Organic formulation. Biopesticide. Cochineal. Hibiscus rosa-sinensis L.

\section{Introdução}

A partir do mapeamento da área verde do Complexo Tecnológico de Medicamentos-CTM, do Instituto de Tecnologia em Fármacos/Farmanguinhos, para implantação do projeto de revitalização paisagística e 
urbana, verificou-se várias infestações de pragas botânicas em várias espécies de plantas ornamentais e da Mata Atlântica (LORENZI, 2013).

Farmanguinhos tem as suas instalações fabris neste complexo, em que se regem as normas nacionais e internacionais de qualidade sanitária, cumprindo assim as Boas Práticas de Fabricação (BPF) e, recentemente, a ISO 14.001, em consonância com a política ambiental da instituição. Contudo, o uso de métodos alternativos fez-se necessário para combater pragas e vetores botânicos, de maneira que não interferissem nocivamente no meio ambiente.

Fonseca e colaboradores (2015) relataram o uso de várias formulações caseiras para o combate de pragas, na região amazônica. Muitas destas formulações utilizam a nicotina presente no fumo de rolo como princípio ativo. Outras formulações eram feitas a base de extrato de pimentas, pulverizadas diretamente sobre as plantas. Cânovas (2008) também propôs para o controle de pragas e vetores a utilização, em separado, de fumo de rolo e pimentas.

Neste trabalho, o uso de uma formulação contendo a mistura de pimentas e o fumo de rolo foi avaliado quanto a eficiência no combate à infestação de cochonilha (Dactylopius coccus) em um indivíduo de Hibiscus rosa-sinensis L, (ROMAHN, 2012) presente no CTM, conforme (FIGURAS 1 e 2).

FIGURA 1: Indivíduo de Hibiscus utilizado para a avaliação da formulação proposta.

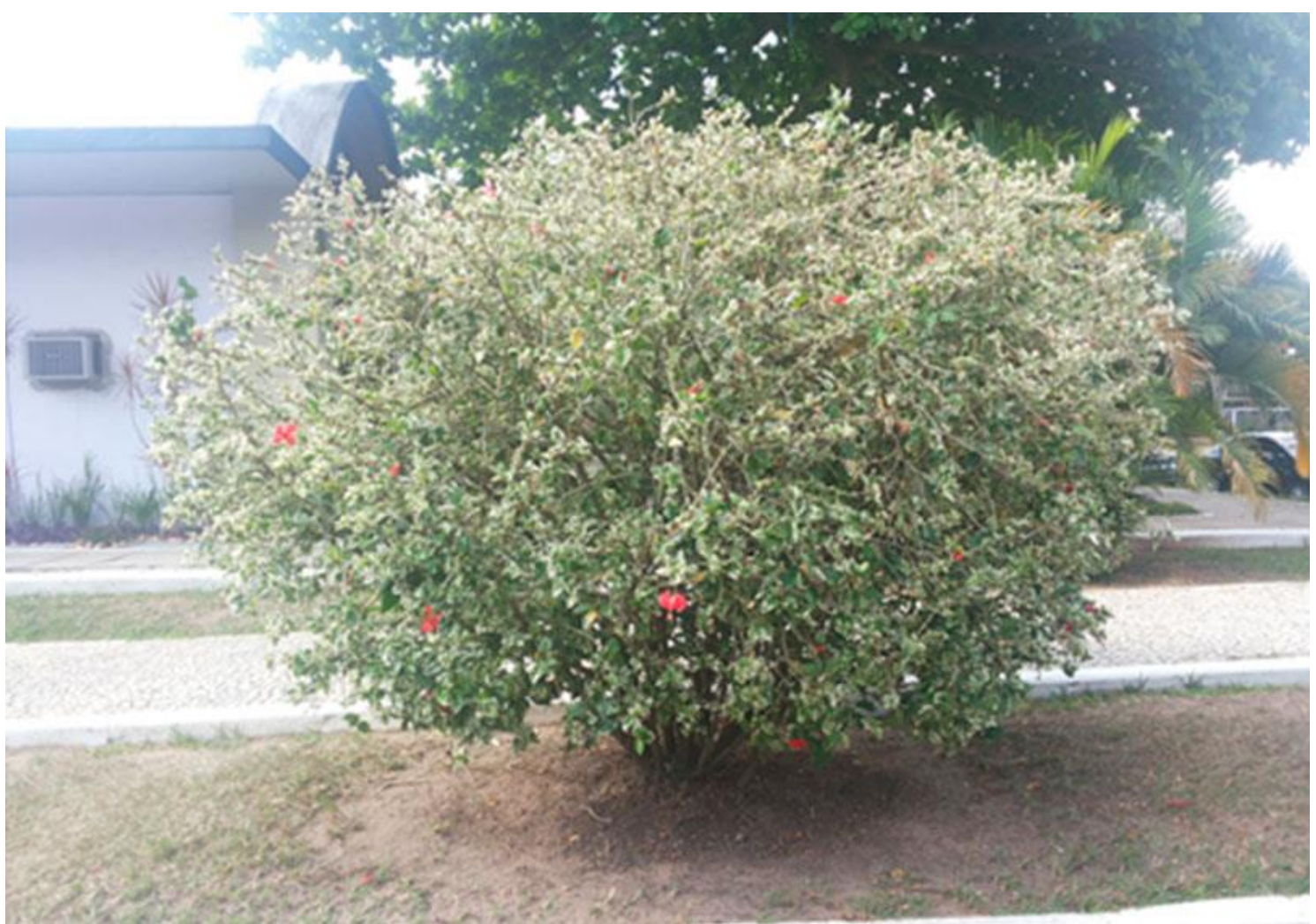


FIGURA 2: Fotografia destacando a infestação de cochonilha. A em destaque as infestações no solo, próximo às raízes.

B em destaque, a infestação na inflorescência.

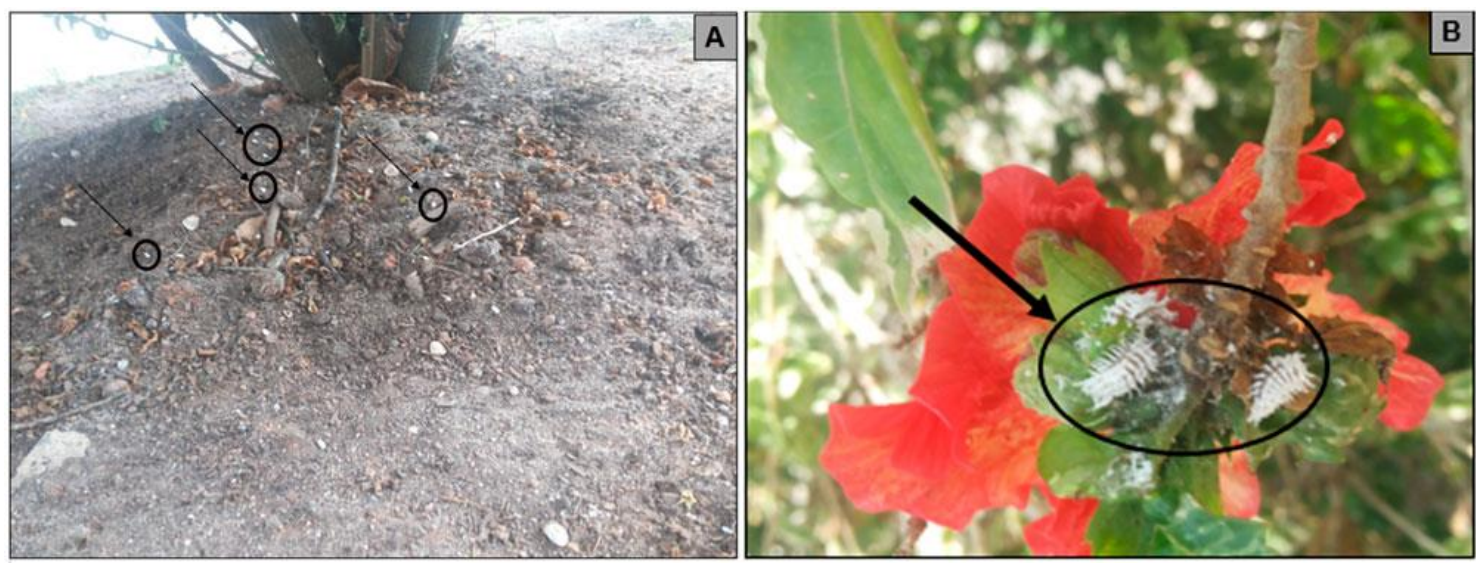

\section{Materiais e Métodos}

A formulação utilizada foi preparada, triturando-se em um recipiente de vidro com tampa, $100 \mathrm{~g}$ de pimenta malagueta (Capsicum frutescens L.), $100 \mathrm{~g}$ de pimenta dedo de moça (Capsicum frutescens). Em seguida, colocou-se $100 \mathrm{ml}$ de álcool 95º, $300 \mathrm{~g}$ de fumo de rolo, $250 \mathrm{~g}$ de sabão de coco em pó e $2 \mathrm{~L}$ de água. A mistura foi homogeneizada e armazenada em um frasco de vidro âmbar por 7 dias. Após este período, acrescentou-se $4 \mathrm{~L}$ de água e filtrou-se a mistura.

Os componentes da formulação foram adquiridos em feira livre (pimentas) e, no supermercado (sabão de coco, álcool 95 e recipiente de vidro).

O Fumo de rolo foi adquirido no Centro de Tradições Nordestinas, localizado no Pavilhão de São Cristóvão - RJ, tendo como fabricante a Empresa Porto Faria, da Cidade de Lassance em Minas Gerais.

A pulverização foi realizada no mês de dezembro de 2014, uma única aplicação entre 14:45 e 14:59 min, sol pleno, temperatura entre $30^{\circ}$ a $40^{\circ} \mathrm{C}$. A infestação deste patógeno está diretamente ligada a esta estação do ano, pois o sol é intenso, o índice pluviométrico é inconstante e o ar é seco. Outra consequência é que estas condições climáticas causam empobrecimento do solo e escassez de nutrientes, e assim, as espécies botânicas ficam mais expostas a pragas.

\section{Resultados}

Inicialmente, o indivíduo apresentava grande área de infestação pela cochonilha, apresentando uma aparência esbranquiçada. A partir da pulverização, o indivíduo foi monitorado a cada 24 horas. Após 72 horas da aplicação da formulação, a infestação reduziu aproximadamente $70 \%$ da área contaminada. Após 7 dias de monitoramento verificou-se que o patógeno foi totalmente erradicado, conforme demonstrado na (FIGURA 3). 
FIGURA 3: Indivíduo tratado com a formulação, sem a infestação de cochonilha.

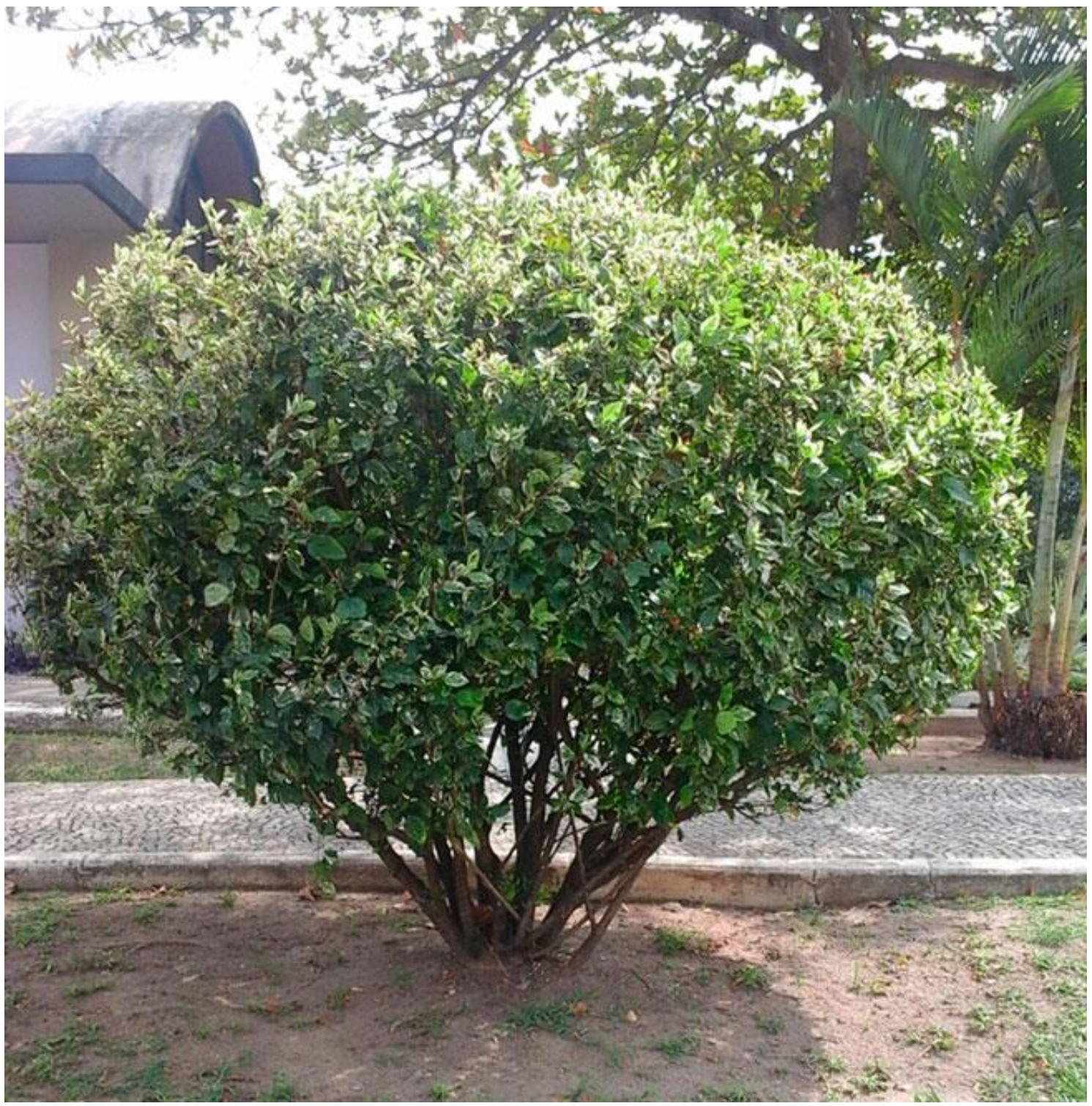

\section{Conclusão}

Baseado nos resultados obtidos pode-se concluir que a associação de duas variedades de pimenta (Capsicum frutescens), em formulações de uso tradicional, é eficiente no combate a infestações de cochonilha, favorecendo o aparecimento de joaninhas (espécie de Coleoptera: Coccinellidae), um dos predadores naturais da praga.

Segundo o levantamento bibliográfico realizado, esta formulação poderá ser utilizada em hortaliças, pois, além de combater e controlar as pragas, a presença do agente emulsificante auxiliou no processo de higienização para o consumo. 


\section{Referências}

FONSECA, J.G.; AYRES, M.I.C.; UGUEN, K.; BASSINI, F.; MENEZES, M. Levantamento e métodos de controle agroecológico de pragas e doenças em propriedades de agricultores familiares da Associação dos Produtores Orgânicos no Amazonas - APOAM. UEA. Cadernos de Agroecologia, v.10, n.3. Manaus. 2015. ISSN 2236-7934. [Link]

LORENZI, H. Plantas para jardim no Brasil: Herbáceas, arbustivas e trepadeiras. Instituto Plantarum, 2013. ISBN 9788586714474.

CÂNOVAS, R. Um jardim para sempre: "Manual prático para manutenção de jardins”. Raul Cânovas, 150p. São Paulo, 2008. ISBN 9788590877004.

ROMAHN, V. Grande enciclopédia ilustrada "plantas e flores". Editora Europa, 2012. ISBN 8945173803.

Conflito de interesses: O presente artigo não apresenta conflitos de interesse.

Histórico do artigo: Submissão: 15/09/2016 | Aceite: 28/09/2017 | Publicação: 25/09/2017

Como citar este artigo: BRAGA, G. S.; COSTA, M. A. G.; ROCHA, A. N. Formulação orgânica eficiente para controle de Cochonilha (Dactylopius coccus) em plantas ornamentais: estudo de caso em Hibiscus rosa-sinensis L. Revista Fitos. Supl. p. 49-53. Rio de Janeiro. 2017. e-ISSN 2446.4775. Disponível em: <http://revistafitos.far.fiocruz.br/index.php/revista-fitos/article/view/405>. Acesso em: 11 maio 2017. Licença CC BY 4.0: Você está livre para copiar e redistribuir o material em qualquer meio; adaptar, transformar e construir sobre este material para qualquer finalidade, mesmo comercialmente, desde que respeitado o seguinte termo: dar crédito apropriado e indicar se alterações foram feitas. Você não pode atribuir termos legais ou medidas tecnológicas que restrinjam outros autores de realizar aquilo que esta licença permite. 